BMC

Genomics

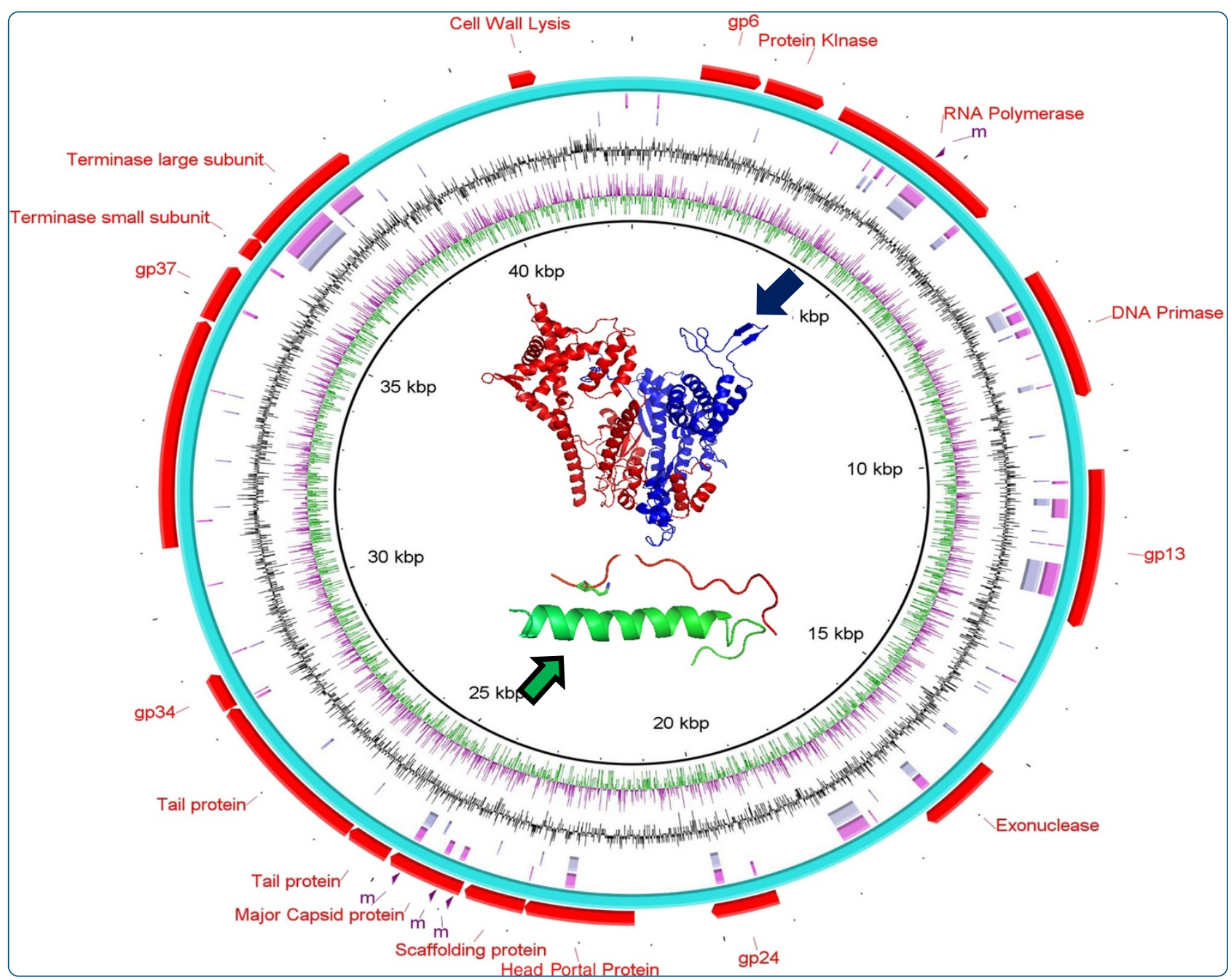

Genome sequences characterizing five mutations in RNA polymerase and major capsid of phages $\phi A 318$ and $\phi A s 51$ of Vibrio alginolyticus with different burst efficiencies

Liu et al. 


\title{
Genome sequences characterizing five mutations in RNA polymerase and major capsid of phages $\phi A 318$ and $\phi A s 51$ of Vibrio alginolyticus with different burst efficiencies
}

Wangta Liư ${ }^{2}$, Ying-Rong Lin ${ }^{1}$, Ming-Wei Lư ${ }^{3}$, Ping-Jyun Sung ${ }^{4}$, Wei-Hsien Wang ${ }^{1,4}$ and Chan-Shing Lin ${ }^{1 *}$

\begin{abstract}
Background: The burst size of a phage is important prior to phage therapy and probiotic usage. The efficiency for a phage to burst its host bacterium can result from molecular domino effects of the phage gene expressions which dominate to control host machinery after infection. We found two Podoviridae phages, фA318 and фAs51, burst a common host $V$. alginolyticus with different efficiencies of 72 and 10 PFU/bacterium, respectively. Presumably, the genome sequences can be compared to explain their differences in burst sizes.

Results: Among genes in $42.5 \mathrm{~kb}$ genomes with a GC content of $43.5 \%, 16$ out of 47 open-reading frames (ORFs) were annotated to known functions, including RNA polymerase (RNAP) and phage structure proteins. 11 strong phage promoters and three terminators were found. The consensus sequence for the new vibriophage promoters is AATAAAGTTGCCCTATA, where the AGTTG bases of -8 through -12 are important for the vibriophage specificity, especially a consensus $T$ at -9 position eliminating RNAP of K1E, T7 and SP6 phages to transcribe the genes. $\phi A 318$ and $\phi A s 51$ RNAP shared their own specific promoters. In comparing $\phi A s 51$ with $\phi A 318$ genomes, only two nucleotides were deleted in the RNAP gene and three mutating nucleotides were found in the major capsid genes.

Conclusion: Subtle analyses on the residue alterations uncovered the effects of five nucleotide mutations on the functions of the RNAP and capsid proteins, which account for the host-bursting efficiency. The deletion of two nucleotides in RNAP gene truncates the primary translation due to early stop codon, while a second translational peptide starting from GTG just at deletion point can remediate the polymerase activity. Out of three nucleotide mutations in major capsid gene, H53N mutation weakens the subunit assembly between capsomeres for the phage head; E313K reduces the fold binding between $\beta$-sheet and Spine Helix inside the peptide.
\end{abstract}

Keywords: RNA polymerase truncation, Spine Helix, Mutation in F-loop

\section{Background}

Vibrio strains are reported to be fatal pathogens not only to humans but also to aquaculture fish and shellfish. Several virulence factors that they produce-including hemolysin, caseinase, gelatinase, lipase, and phospholipase-are detrimental to animal health [1-4]. For instance, an extracellular protease with endopeptidolytic and exopeptidolytic activities from a pathogenic $V$. pelagius strain is responsible for the lethal effect and vibriosis in turbot.

\footnotetext{
* Correspondence: shinlin@faculty.nsysu.edu.tw

'Department of Marine Biotechnology and Resources, Asia-Pacific Ocean Research Center, National Sun Yat-sen University, Kaohsiung 80424, Taiwan Full list of author information is available at the end of the article
}

The different virulence factors are produced at different stages of infection. Hemolysin-producing bacteria include $V$. parahaemolyticus, $V$. alginolyticus, $V$. cholerae, $V$. hollisae, Aeromonas veronii, and V. anguillarum (Listonella anguillarum).

Vibrio alginolyticus, a Gram-negative halophilic bacterium that frequently occurs in the normal microbiota of marine environments, is a pathogen of epizootic outbreaks, which causes serious mortality of fish and shellfish and also can transmit to humans. The disease caused by $V$. alginolyticus often has lethal consequences for fish larvae throughout the world, and it has become one of the

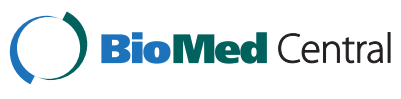

(C) 2014 Liu et al.; licensee BioMed Central Ltd. This is an Open Access article distributed under the terms of the Creative Commons Attribution License (http://creativecommons.org/licenses/by/2.0), which permits unrestricted use, distribution, and reproduction in any medium, provided the original work is properly credited. The Creative Commons Public Domain Dedication waiver (http://creativecommons.org/publicdomain/zero/1.0/) applies to the data made available in this article unless otherwise stated. 
major limiting factors in aquaculture in developing countries. For example, it was a causal agent of vibriosis outbreaks in grouper sea bream Sparus aurata [2]. V. alginolyticus causes several symptoms in sea bream: septicemia, hemorrhaging, dark skin, and ulcers on the skin surface. Some fish accumulate fluid in the peritoneal cavity or have hemorrhagic livers. In several cases of high-mortality outbreaks, Vibrio alginolyticus and Vibrio splendidus biovar II were the primary organisms found in moribund clam larvae (Ruditapes decussatus), and these two species processed extracellular products collaboratively at high concentrations to kill the hemocytes after four hours of incubation. Neurotoxic effects caused by the supernates from diseased strains of Vibrio alginolyticus and Vibrio anguillarum caused several symptoms in trout, including convulsions, wriggling, contortive swimming and respiratory arrest [2].

Chemotherapeutic agents are effective to control pathogenic bacteria in aquaculture. Nevertheless, emergence of antibiotic-resistant bacteria has become a critical issue [3]. As a result of management practices in production cycles, the use of probiotics to prevent pathogenic bacterium growth in aquaculture is a practice to reduce both issues on antibiotic resistance and drug residues in food. One alternative is to use bacteriophages to control bacterial growth, which is similar to phage therapy in medical care. This idea has been proposed as a cure for coral disease [5]. A variety of bacteriophages that can quickly lyse the pathogens have high potential for future applications in aquaculture.

The burst size of a phage represents an overall outcome that is so important for phage therapy and probiotic usage. The molecular interactions between phage and its host under certain environmental conditions are complicated to resolve. Sequences of bacteriophage genomes provide a magnificent tool to investigate interactions with hosts. In addition, vibriophages can be used as a new typing scheme for pathogen identification and as candidate agents for phage therapy and probiotics. For example, the roles of lytic bacteriophages in cholera epidemics were investigated, such as filamentous CTX $\phi$, myovirus ICP1, and podovirus ICP3 of Vibrio cholerae, causing infant and adult deaths for centuries [6]. Though quite a large number of Vibrio phages have been described, only a few of complete genome sequences are known. Genome sequences of lytic vibriophages are new keys for molecular typing, pathogenesis, and even assessment of therapeutic efficacy. Complete genomes of some phages of $V$. cholerae, $V$. parahaemolyticus, and $V$. vulnificus were documented, yet no genome for $V$. alginolyticus podovirus has been reported. In this study, we characterized the genome sequences of two newly-isolated phages that can lyse $V$. alginolyticus ATCC 17749 with different efficiencies.

\section{Results}

\section{Host range, burst size, and thermal stability}

The plaques of $\phi A 318$ that formed in 4 hours at $25^{\circ} \mathrm{C}$ were very clear at their center and at the margin of the edge; sizes of the plaques were about $3 \mathrm{~mm}$ in diameter, which increased to $5 \mathrm{~mm}$ overnight (Figure 1A). The phage concentration in each plaque infected and fully lysed the amounts of host bacterium up to a 50x volume ratio. In comparison, the plaque size of $\phi A s 51$ only reached $1 \mathrm{~mm}$ overnight (Figure $1 \mathrm{~A}$ ), and the amplification should not be greater than $3-5 x$ dilution ratio. The EM morphology of phages \$A318 and фAs51 was indistinguishable from each other. The icosahedral head was almost isometric, with a size of 50-55 nm, and the shells on the head capsids sketched out at least three visible rings, although the tail fiber was barely distinguishable from the capsid shell in the micrograph (Figure 1B). The tail was $12 \mathrm{~nm}$ long, elongating from $25 \mathrm{~nm}$ wide in the head-neck connector to $5 \mathrm{~nm}$ in the nozzle. They are highly similar to the bacteriophages of the family Podoviridae [7].

The susceptibility of other Vibrio strains to phage

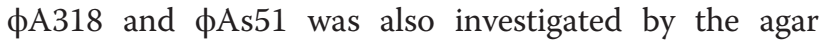
overlay method. Among six other Vibrios, V. damsela and $V$. harveyi were found to be susceptible to both phages фA318 and \$As51, while the other four species could not be infected even at an MOI of more than 100. For measurement of the burst size, a bacterial culture in the early exponential growth phase was split into glass tubes with equal numbers of $V$. alginolyticus cells $(\mathrm{MOI}=1.0)$, and then plaque titers were calculated within 4 hours of incubation. According to the one-step method [8], the burst size of phage $\phi A 318$ was 72 PFU per infected cell, while that of $\phi A s 51$ was $10 \mathrm{PFU} /$ cell (Figure 1C).

A thermal stability test was carried out to analyze the heat resistance of phages at $\mathrm{pH}$ 7.5-8.0. The phages were incubated at $25-80^{\circ} \mathrm{C}$ for one hour. As Figure $1 \mathrm{D}$ shows, the relative phage titers were measured at different temperatures. After incubation at $50^{\circ} \mathrm{C}$ for one hour, phage \$A318 retained almost $100 \%$ infectivity, while $\phi A s 51$ decreased to $80 \%$. When the temperatures rose higher than $70^{\circ} \mathrm{C}$, nearly all phages were inactivated after 15 minutes of incubation.

\section{The $\phi A 318$ genome}

фA318 genome was sequenced by a combination of shotgun sequencing (Figure 2 and Table 1 ). Open reading frames (ORFs) were determined using a combination of RAST visual inspection and translated tBLASTx searches [9]. The genome consists of a single double-stranded DNA molecule of 42544 bp with a GC content of $43.5 \%$. We have annotated 47 open reading frames (The genome was submitted to GenBank with access no. KF322026 for phage фA318; [GenBank:KF322026]; Additional file 1: annotation 


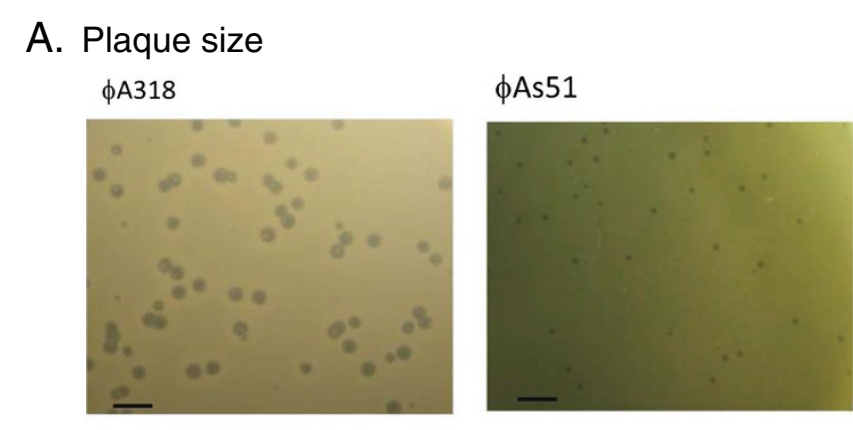

B. TEM micrograph

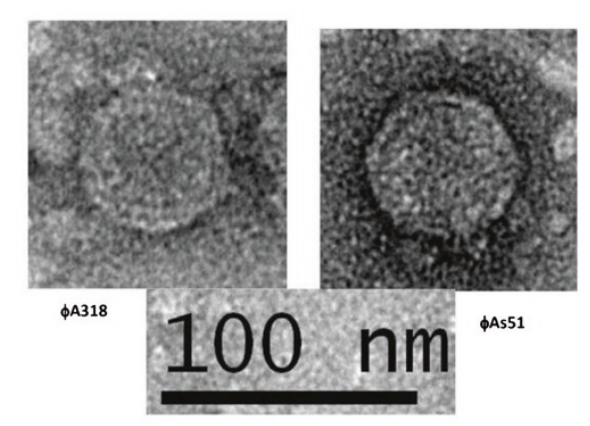

C. Burst size

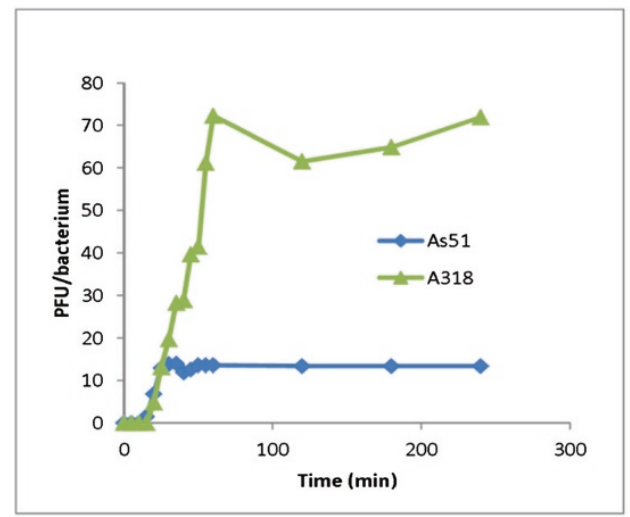

D. Thermal stability

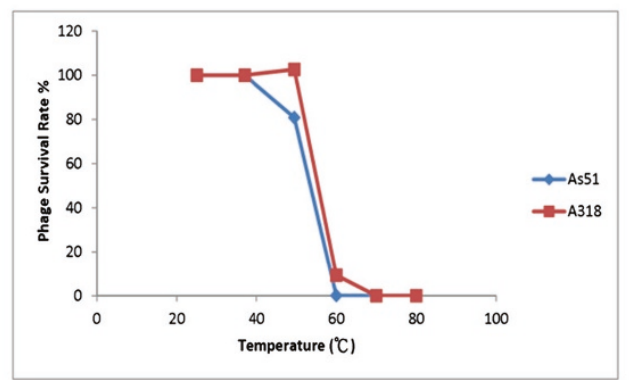

Figure 1 (See legend on next page.) 
for $\phi A 318$ genome), all but one of which are transcribed on one strand of the DNA molecule. The $\phi A 318$ genome is flanked by some terminal repeats. It is a tightly packed genome with $\sim 90 \%$ of the sequence predicted to encode proteins. We use the same gene-numbering system by RAST PEG, starting from left to right on the genetic map, similar to that of K1E and SP6 since the genomes are analogous in organization of major predicted sequences (Figure 2A). ORFs that have no sequence similarity to any previously characterized Podoviridae phages are simply painted in gray (Figure 2B). Like phage K1E, as well as other T7-like phages, the $\phi A 318$ genome can be divided into three regions: early, middle, and late (Table 1). The first predicted gene similar to other genomes is gp6, which is likely to be of unidentified function in SP6. Other than the endosialidase (see below), most open reading frames carried by $\phi \mathrm{A} 318$ are comparatively more similar to phages $\mathrm{K} 1 \mathrm{E}$ and SP6 than to T7 and other known podoviruses that infect Vibrio. \$A318 encodes an RNA polymerase (RNAP of PEG 5; gene 1.0 or K1Ep10) which is responsible for transcription of most of other phage genes that are involved in DNA replication, maturation, and packaging [10]. An adenylation DNA ligase-like gene (PEG 24, gene 1.3) is analogous to that of SP6p25 or K1-5 gp24 and is present at the end of the Class II genes. The middle region encodes mainly proteins involved in DNA replication/metabolism, among which only primase/helicase (PEG 9, gene 4.0), DNA polymerase (DNAP; PEG 12, gene 5.0), and exonuclease (PEG 19, gene 6.0) were annotated functionally.

With the high similarity to other phages, the late region of the $\phi A 318$ encodes the virion structural proteins as well as many of the proteins involved in maturation and cell lysis. The $\$$ A318 PEG 29 is the head-tail connector (gene 8.0), followed by those coding for the scaffolding protein (gene 9.0), capsid (gene 10.0), tail tube (genes 11.0 and 12.0), and internal virion proteins (gene 13.0-16.0). The genes coding for maturation and terminases subunits (genes 18 and 19.0) were found in PEGs 39 and 40. Perhaps the PEG 37 ( gene 17) coded for the product with only a small region of amino acid similarity to the T7 tail fiber at the $\mathrm{N}$-terminal head-binding portion, whereas the central catalytic region is highly similar to that of phage K1E endosialidase which may be involved in both recognition and depolymerization of the $\mathrm{K} 1$ polysaccharide capsule.
Like most of members of the closely-related T7 family, $\phi A 318$ is flanked by terminal repeats, suggesting similar replication strategies: phiL-122, 124, and 126 were promoter-like and repeats. Promoter sequences for most gene transcription among T7 supergroup phages, which are driven by phage-encoded RNAPs, are recognized very specifically. $\phi A 318$ encodes an RNAP with highly conserved motifs to that of T7. Employing the UGENE program for searching at repeats with the conditions of $>13$ bases and $>95 \%$ homology, we predicted 16 promoter consensus sequences from 126 repeat regions: 11 putatively strong promoters and six weak ones. Most of those have T7-like homologues (Figure 3). The consensus sequence from -7 to +1 is identical to that of T7, except that A at -6 was replaced by $\mathrm{C}$. However, bases of -8 through -12 , which are important for promoter specificity, differ from T7, T3, K11, and SP6 [10,11]. The consensus at -9 for T7 and SP6 is $C$, any change leading to inactive [10]. Since $\phi A 318$ and K1E have $\mathrm{T}$ and G, respectively, at this position, it is unlikely that the T7 or K1E RNA polymerase will initiate transcription from $\phi A 318$ promoters. $\phi A 318$ RNAP has different promoter specificity.

фA318 appears to have phage promoters throughout the region of the T7 analogues. We proposed that the promoters of phi122, phi124, and phi125 in $\phi A 318$ are equivalent to $\phi O R$ involved in packaging and possibly replication [10]. Unlike phages gh-1 and K1E, one phagespecific promoter (phi-A8 at position 1741) was found immediately upstream of the protein kinase and RNA polymerase genes in $\phi A 318$, suggesting that the autoregulation controls these two genes together. The genome contains a strong $\sigma 70$ promoter (at 229-257 nt) responsible for early gene transcription, including phage RNA polymerase. The end of transcription of the early genes in $\mathrm{A} 318$ is marked by GCCCTGATtcttaatgagTCAGGGC TTTT CTT, a rho-independent terminator (TE, near position 5957) immediately following the RNA polymerase gene, the equivalent position at 7128 to 7161 in K1F of such terminator. PEG 4 in $\phi A 318$ is similar to gene 0.7 in T7, which could encode a kinase to phosphorylate host RNAP and efficiently inactivate the host gene expression [12]. Two terminators, GCCCCTGCCtactttGGTAGGGG CTTATTTTT at position 24971 and GAGGGACT cctaag AGTCCCTCcTTTCTT at position 38217, were found. Terminator at 24871 was a potential analogue to the T7 

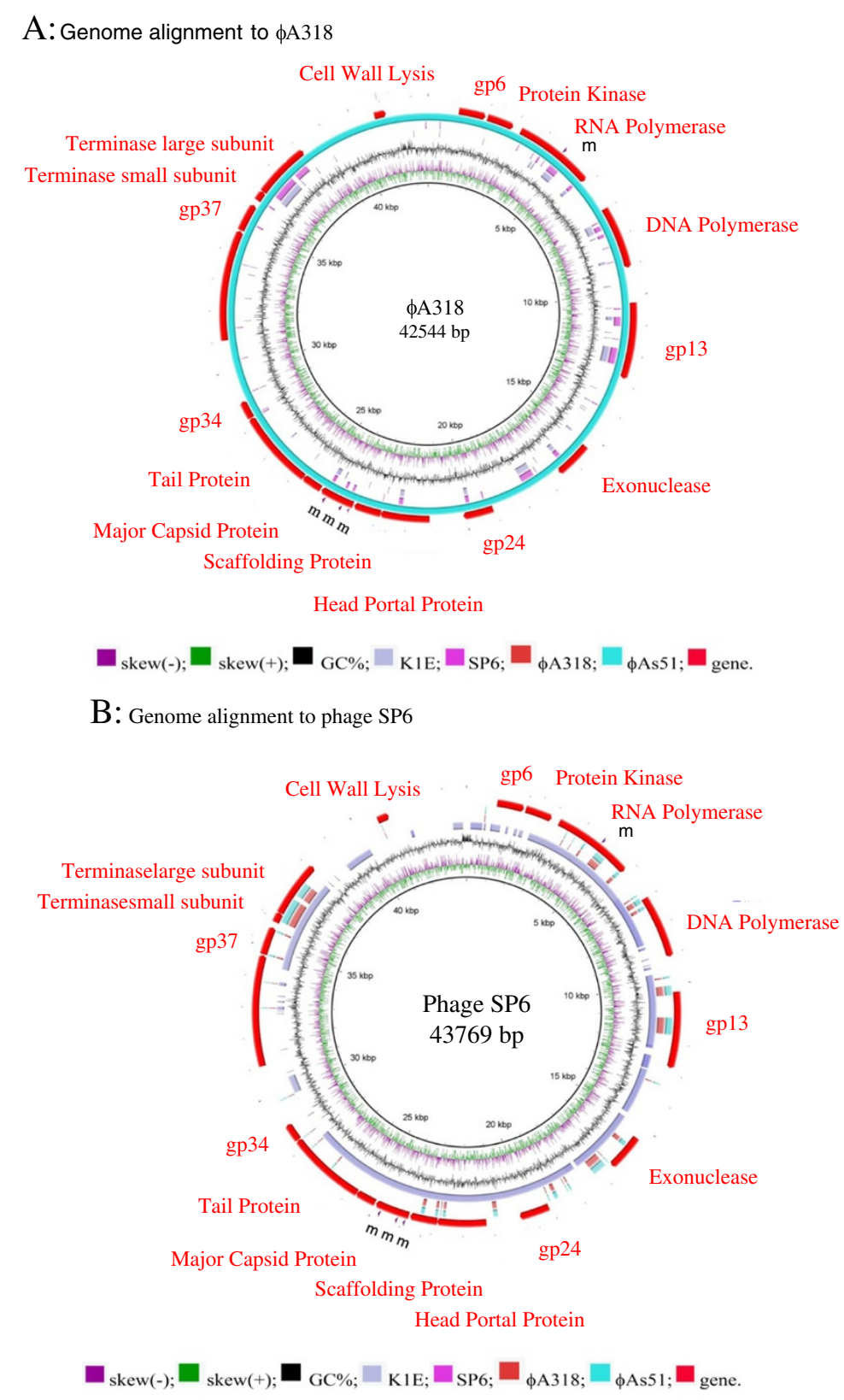

$\mathrm{C}$ : Genome alignment by aggressive Mauve

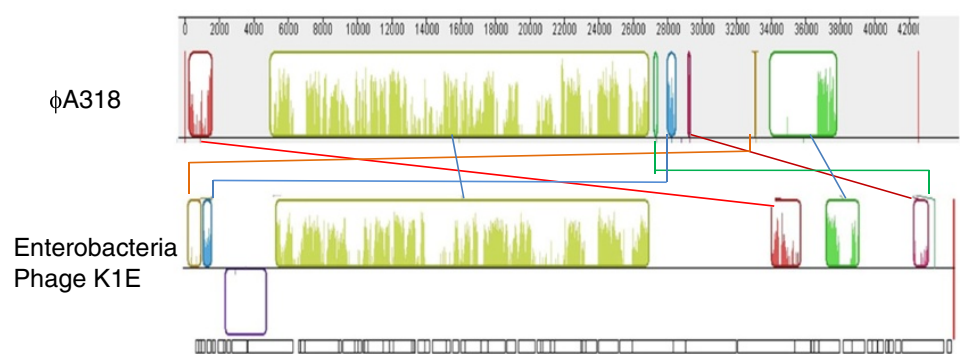

Figure 2 (See legend on next page.) 
(See figure on previous page.)

Figure 2 Genome alignment and annotation for phages $\phi A 318$ and $\phi A s 51$ with the genomes from phages SP6 and K1E. (A) Genome alignment using query of $\phi A 318$ against to phages $\phi A s 51, S P 6$ and $K 1 E$, (B) Alignment using query of SP6 against phages K1E, $\phi A 318$, and фAs51. фAs51 map is highly similar to фA318 with 5 single nucleotide mutations (marked by $\mathrm{m}$ ) and annotation as shown in Table 1 and GenBank access no. KF322026 and KF800937. This draw was done by BLAST [9] and Ring Image Generator [32]. Purple line represents skew(-); green for skew(+); black for GC\%; grey for K1E; pink for SP6; blur red for фA318; cyan for $\phi A s 51$; red for specific genes. (C) Mauve was used to efficiently construct multiple genome alignments, which provides a basis for research into comparative genomics among phages $\phi A 318$ to its related phage $\mathrm{K} 1 \mathrm{E}$.

$\mathrm{T} \phi$ terminator, located inside the gene encoding major capsid; terminator at 38217 was just the end of tail fibers.

\section{Genome comparisons between $\phi A 318$ and $\phi A s 51$}

Analyses of nucleotide restriction enzyme polymorphisms and protein profiles showed no difference between $\phi A 318$ and $\phi A s 51$ (data not shown); the amplification rates were, however, significantly distinct for the two phages. It was worth-while to sequence the whole genomes to investigate the context. $\phi$ As51 genome of 42542 bp (GenBank access no. KF800937; [GenBank:KF800937]; Additional file 2: annotation for $\phi$ As51 genome) was almost the same as $\phi A 318$, except that five single nucleotides were mutated sporadically in the genome. Triple checks by PCRs and re-sequencings showed that two deletions of Adenosine were in RNAP gene while single-nucleotide mutations in three sites also occurred in the major capsid protein.
In comparison with gene sequences of other T7-like RNA polymerases, $\phi A 318$ and $\phi A s 51$ RNAP genes shared five consensus regions, corresponding to residues $421-425,537-538,563-575,627-641$, and 811-813 residues in the T7 RNA polymerase. As shown in our previous publication [7], the motifs were highly conserved among the T7-like phages. In phage $\phi A 318$, the sequences of the motifs were DFRGR (motif T7-421), DG (motif T7537), PSEKPQDIYGAVS (motif T7-563), RSMTKKPVM TLPYGS (motif T7-627), and HDS (motif T7-811), respectively. In the region of $\phi A s 51$ RNAP gene, two nucleotides were deleted at $1545 \mathrm{nt}$, resulting in that the RNA polymerase molecules were translated into two pieces: one N-term fragment of the 515 residues plus three additional residues and the second fragment for C-term with just one additional Met as a start codon (Figure 4A). The analysis of nucleotide sequence revealed that the ribosome binding site AGAAGAAT upstream of a GTG was

Table 1 The genes in genomes of phages $\phi A 318$ and $\phi A s 51$ were annotated to known functions

\begin{tabular}{|c|c|c|c|c|c|c|c|}
\hline Class & T7 & K1E & $\phi A 318$ ORF & Start & End & Function & Aliases \\
\hline I & gene 0.3 ? & & 3 & 1023 & 1916 & gp6 protein & Inhibits EcoB and EcoK host restriction \\
\hline I & gene 0.7 & & 4 & 1990 & 2886 & protein kinase & \\
\hline I & gene 1 & gene 7 & 5 & 3173 & 5957 & RNA polymerase* & фAs51: $3173 . .4727$ and $4615 . .5955$ \\
\hline$\|$ & gene $4 \mathrm{~A}$ & gene 9 & 9 & 6997 & 9093 & DNA primase & \\
\hline$\|$ & gene 5 & & 12 & 10263 & 12806 & gp13 & Putative DNA polymerase \\
\hline$\|$ & gene 6 & & 19 & 16306 & 16599 & hypothetical protein & Era10.24 Phage exonuclease 40.13 \\
\hline I & gene 1.3 & & 24 & 19109 & 20107 & gp24 & SP6p25 Adenylation_DNA_ligase_like; K1-5 gp24 \\
\hline III & gene 8 & gene 29 & 29 & 21233 & 22861 & head portal protein & \\
\hline III & gene 9 & gene 30 & 30 & 22861 & 23769 & scaffolding protein & \\
\hline III & gene 10B & gene 31 & 31 & 23817 & 24968 & major capsid protein* & \\
\hline III & gene 11 & gene 32 & 32 & 25042 & 25689 & tail protein & \\
\hline \multirow[t]{2}{*}{ III } & gene 12 & gene 33 & 33 & 25692 & 28313 & tail protein & \\
\hline & & gene 34 & 34 & 28323 & 28928 & gp34 & K1E gp34 internal protein \\
\hline III & gene 13 & gene 36 & 36 & 31035 & 34724 & internal virion protein & \\
\hline III & gene 17 & gene 37 & 37 & 34759 & 35694 & gp37 & $\begin{array}{l}\text { K1E endosialidase adaptor protein; SP6gp38 } \\
\text { tail fiber/adaptor }\end{array}$ \\
\hline III & gene 18 & gene 39 & 39 & 35889 & 36233 & hypothetical protein & Era10.45 Phage terminase, small subunit 33.01 \\
\hline \multirow[t]{3}{*}{ III } & gene 19 & gene 40 & 40 & 36233 & 38107 & large terminase subunit & \\
\hline & & & 44 & 40747 & 41136 & similar to cell wall hydrolyses & \\
\hline & & & & & & involved in spore germination & \\
\hline
\end{tabular}




\begin{tabular}{|c|c|}
\hline Promoter Name & \\
\hline & $\ldots|\ldots| \ldots \mid \ldots$ \\
\hline A318_6016 & ААTAAAGTTGCССТАTAGGAGAG \\
\hline A318_6097 & T...........АTT.A \\
\hline A318_9088 & -T.T......... АTA.T \\
\hline A318_9221 & GTG..G..GA.G....G.CTC.A \\
\hline A318_12924 & ... . . . . . . . ATAGA \\
\hline A318_13255 & $\ldots$. . . . . . . \\
\hline A318_14876 & $\ldots$ Т......... ATA \\
\hline A318_19983 & GT.TTGTGCA. . . . . TA. A \\
\hline A318_20106 & . . . . . . . . АTA.C \\
\hline A318_23768 & $\ldots$ т......... АTA.С \\
\hline A318_34720 & $\ldots \ldots$ G. . . . . . TA.A \\
\hline A318_1738 & СС.T.С.С. . TA. . GGATTAG. \\
\hline A318_16310 & -.СT.C.C..TA...GGT.C.T- \\
\hline A318_41944 & TC. TGGAGC. TA. . GTATTTGC \\
\hline A318_41999 & .С. TGGAGC.TA. . . GСTATTGC \\
\hline A318_42153 & TC. TGGAGC. TA. . GTAA. TTC \\
\hline T7 & T.AT.C.ACT.A.....GAGA \\
\hline SP6 & .T.T.G..GA.A.....A. .A \\
\hline K11 & ...T.G.GCA.A. . . . GAGA \\
\hline T3 & .....СССТ.А...А...GAGA \\
\hline \multicolumn{2}{|c|}{$\begin{array}{l}\text { Figure } 3 \text { The sixteen promoters in phage } \phi A 318 \text { genome were } \\
\text { predicted and aligned with those of T7, SP } 6, \mathbf{K} 11 \text {, and T3 } \\
\text { phages. The position of each promoter in } \phi A 318 \text { genome was } \\
\text { recorded as the number following the name of phage. The names } \\
\text { of predicted promoters are given using their positions in } \phi A 318 \\
\text { genome, while the positions are shifted by two nucleotides in } \\
\phi A s 51 \text { genome. }\end{array}$} \\
\hline
\end{tabular}

suitable for the second translation of $\phi A s 51$ RNAP gene to a product of the exactly same sequence as the C-term of QA318 RNAP. With use of the threading method of $\mathrm{PHYRE}^{2}$ to predict the 3-dimentional structures for these two fragments of $\phi A s 51$ RNAP, the result revealed that the truncation join was located in the junction of palm and fingers. As Figure 4B shows, the tail of $\phi A s 51$ RNAP $\mathrm{N}$-term fragment formed a clip (arrows) to hold the QAs51 RNAP C-term fragment at the position on palm.

Three mutations of single nucleotide were all in the first codon of the residue, and therefore, totally altered the residues. The mutation at 23973th nucleotide resulted in mutating Histidine at 53th residue to be Asparagine $(\mathrm{H} 53 \mathrm{~N})$; 24171th nucleotide mutation changed Isoleucine at $119^{\text {th }}$ to Valine (I119V); and $245789^{\text {th }}$ nucleotide mutation converted Glu-313 to Lys-313 (E313K). The structures of $\phi A 318$ and $\phi A s 51$ major capsid proteins were predicted from models of HK97 and T7 capsids by PHYRE $^{2}$ with $>93 \%$ confidence. In comparing with the $\phi A 318$ capsid, the mutation effects of Asn-53 on фAs51 major capsid protein broke the presumed cation bridge between His-53 of two capsomere subunits in фA318 capsid (Figure 5A and C). Glu-313 residue of $\beta$ J in $\mathrm{P}$-domain formed two hydrogen bonds with the $\mathrm{O}=\mathrm{C}$ of the backbone of the Spine Helix to stabilize the link between three beta-sheets and one helix (Figure 5B). However, E313K mutation in $\phi A s 51$ caused the $\beta \mathrm{J}$ in P-domain to lose two hydrogen bonds so as to destabilize the link on the Spine Helix (Figure 5D).

\section{Discussion}

This is the first Podoviridae genomes of Vibrio alginolyticus phages that are documented in GenBank. 16 out of 47 ORFs were annotated to known functions, while other ORFs were similar to enterobacteria phages $\mathrm{K} 1 \mathrm{E}$ and SP6. 11 strong phage promoters and three terminators were predicted, which are located slightly differently from the closest partners, though genomic organizations were highly homologous [10,12]. Most of promoters have T7-like homologues, except that $\mathrm{A}$ at -6 was replaced by $\mathrm{C}$ and specificity region on -8 to -12 (Figure 3 ). In $\phi A 318$ and $\phi A s 51$ phage promoters, the consensus sequence from -7 to +1 is CCCTATAG. However, bases of -8 through -12 , which are important for promoter specificity, differ from T7, T3, K11, and SP6. The consensus at -9 for T7 and SP6 is C; any change of this nucleotide inactivates the promoter function [10]. Since $\phi A 318$ and K1E have T and G, respectively, at this position, it is unlikely that the T7 or K1E RNA polymerase will initiate transcription from $\phi \mathrm{A} 318$ promoters. $\phi \mathrm{A} 318$ RNAP has different promoter specificity. This exclusivity of promoter specificity seems to be the trend among the T7-like phages, and it seems that there must be some selective pressure that resulted in this feature.

Electron microscopy revealed that phage $\phi \mathrm{A} 318$ and фAs51 particles were morphologically similar to type C in Bradley's classification of Podoviridae phage (Figure 1) [13]. The podovirus family is characterized by phages with a nearly isometric icosahedron head and a short non-contractile tail $[13,14]$. Furthermore, the lengths of the icosahedral capsid and tail of phage $\phi A 318$ were morphologically indistinguishable from those typically observed for $\phi$ As51.

In phages $\phi A 318$ and $\phi A s 51$, the sequences of the motifs were DFRGR (motif T7-421), DG (motif T7-537), PSEKPQDIYGAVS (motif T7-563), RSMTKKPVMTLPY GS (motif T7-627), and HDS (motif T7-811), respectively. Strikingly, two nucleotides were deleted in the region of \$As51 RNAP gene, which resulted in the RNA polymerase molecules being translated into two pieces separated at the 515 th residues (1545 nt); the $\mathrm{N}$-term fragment increased three additional residues in its C-terminus while the second fragment started from a suitable upstream ribosome binding site AGAAGAAT and added just one codon GTG for Met to form exactly the same product as the C-term of $\phi A 318$ RNAP (Figure 4A). We suggested that the two fragments could form a 2-subunit-like 


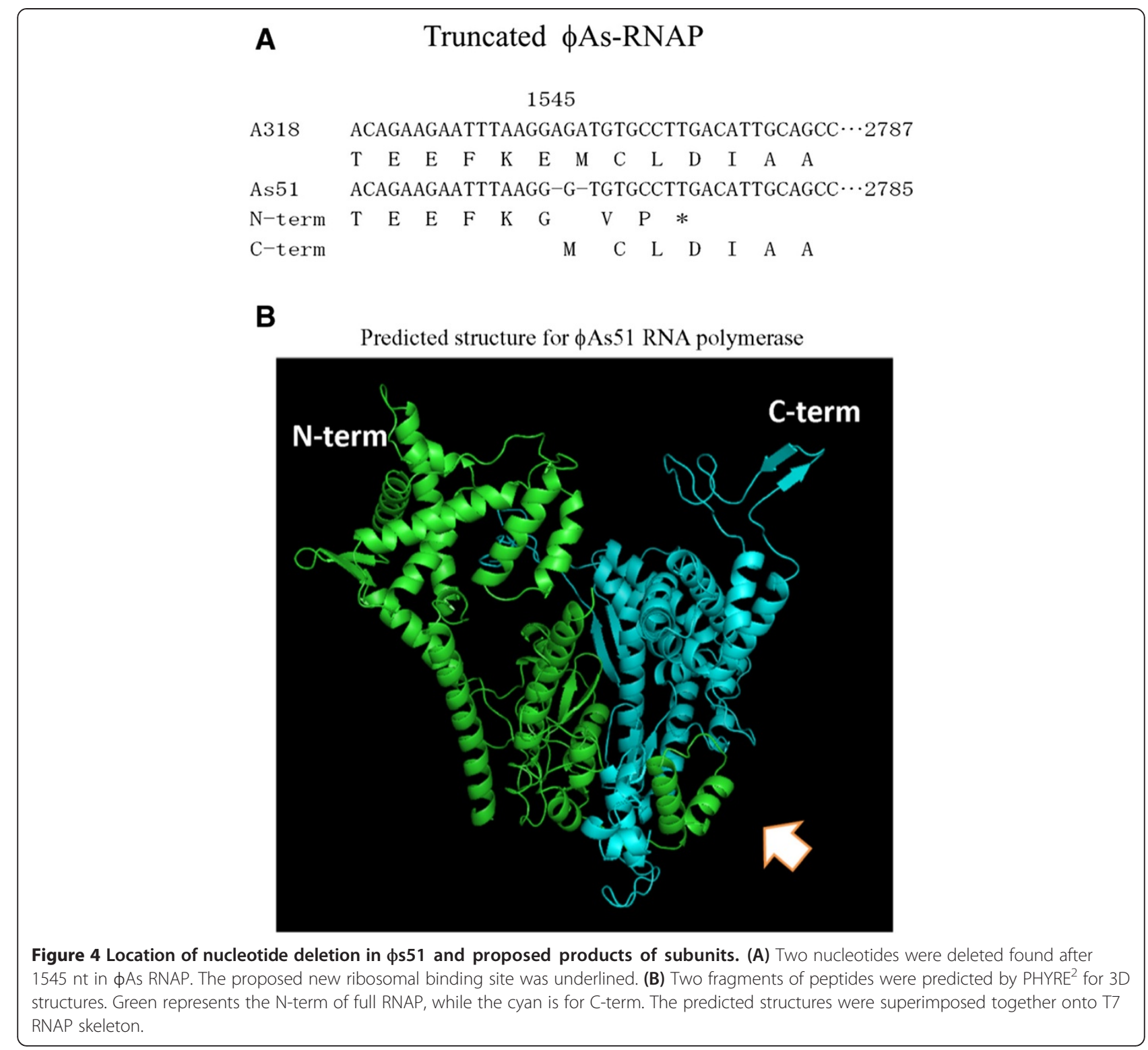

enzyme to function for the RNA polymerization but weaken RNAP and lose $88 \%$ bursting ability.

Virus maturation corresponds to a transition from an initial non-infectious to an infectious and robust virion. PHYRE2 matched the major capsid protein of $\phi A 318$ and фAs51 to phage T7 capsid structure PDB:3IZG [15,16]. The 3-dimentional prediction clearly revealed that the capsids of the two new phages were characterized by A-domain, Spine Helix, P-domain, E- and F-loops. Three $\beta$-strands are located in P-domain, where $\beta J$ is in the center of the three. The matches of residues, however, were not by one-on-one basis. The 53th residue of $\phi A 318$ and $\phi A s 51$ capsid was ruled onto $156^{\text {th }}$ residue in F-loop of PDB:3IZG while 115-135th residues of $\phi A 318$ and фAs51 were corresponding to 170-190th residues of Spine
Helix in PDB:3IZG. The prediction clearly showed Spine Helix and $\beta J$ is located in P-domain. The pair of His53 is in the F-loops of two capsomere subunits or between the subunit $G$ and hexamers. A fusion of the scaffolding protein to be $\delta$-domain, residues $2-103$, in HK97 capsid was not found in the new phages, suggesting that the dynamic of forming matured capsid of $\phi A 318$ and $\phi A s 51$ may differ from HK97. Based upon our predicted capsid that was well aligned with the structure of residues 104-385 in the HK97 coat subunits, which form a mixture of hexameric and pentameric capsomeres upon expression, they may still share some degree of expansion intermediates with the HK97 capsid [17]. For example, 415 coat subunits (60 hexamers and 11 pentamers) assemble with a dodecameric portal and $\sim 60$ copies of the viral protease to 
A His-53 in $\phi$ A318 major capsid

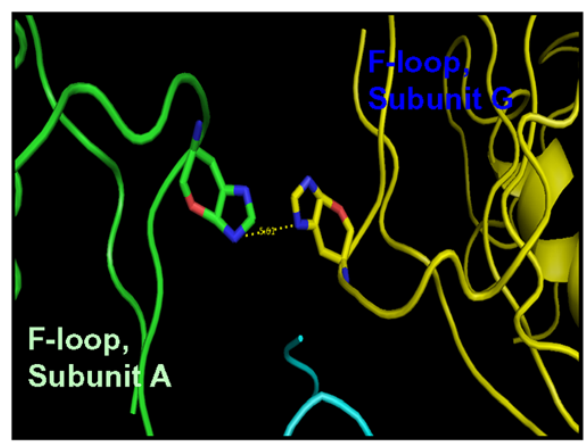

C Gln-53 in $\phi A 51$ major capsid

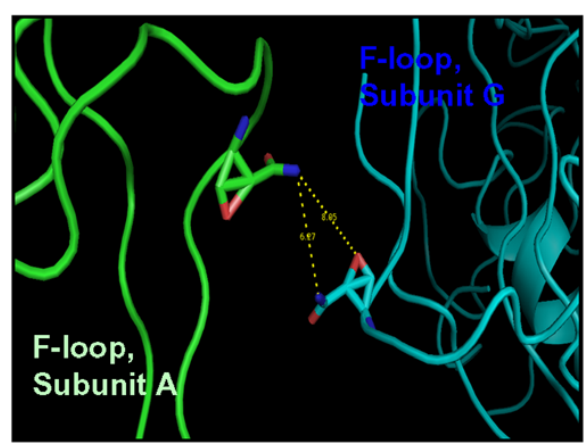

B Glu-313 in $\phi$ A318 major capsid

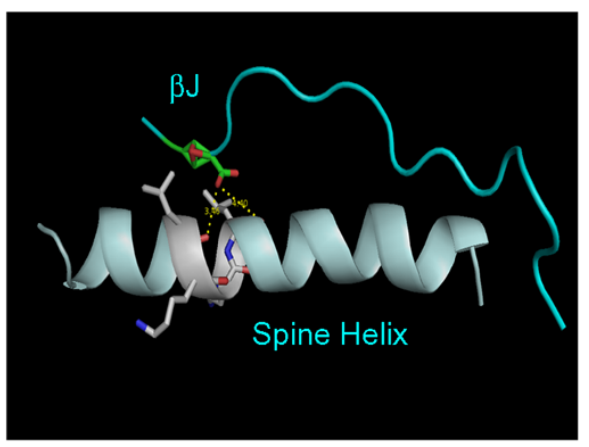

D Lys-313 in $\phi A 51$ major capsid

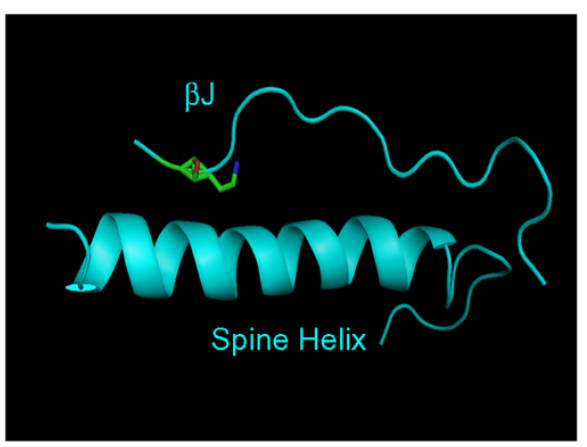

Figure 5 Point mutations found in $\phi A s 51$ and losses of interaction in the predicted structures of subunits. Dot lines between atoms represent the distances. $\beta \mathrm{J}$ is located in P-domain. The pair of His-53 is in the F-loops of two capsomere subunits or between the subunit G and neighboring hexamer.

form proheads; or the prohead particles exhibit spine helix bent and P-domain $\beta$-sheet twist. Veesler et al. [17] used an HK97 subunit mutation that prevents formation of non-covalent interactions in virus-like particles and stops maturation at the expansion intermediate of the particles without E-loop "chainmail" interactions. Our results of \$As51 also showed E313K in $\beta J$ may be involved in the spine helix bending and P-domain $\beta$-sheet twisting, while H53N mutation may prevent non-covalent interactions of E-loop chainmail. When Histidine at 53th is present in the F-loop, adjacent to E-loop, divalent cations like $\mathrm{Ni}^{2+}$ and $\mathrm{Ca}^{2+}$ will build a bridge for such interactions.

Capsid instability in $\phi A s 51$ with residues Asn-53 (53 N) and Lys-313 (313 K) can account for the thermal stability data in Figure 1. We proposed that the deletion effects of RNAP contributed higher percentages of losing burst ability for $\phi$ As51 phage than the point mutations occurring in the major capsid protein. Our findings suggest that the genome sequencing provides a security check prior to application of phages in therapy; thereafter, the mutation rate for each hotspot can be validated for managing the medication plan. The complicate mechanisms still lie ahead for us to solve. Once phage decreases gene activities, the host gains a niche to suppress the phage propagation; as a seesaw does [11]. Further investigations will discover the details.

\section{Conclusions}

Five nucleotide mutations sporadically spread in the фAs51 genome of about 42500 nucleotides. Those small differences may be the causes to distinguish the lower propagation ability and thermal tolerance of $\phi A s 51$ from the superior $\phi A 318$ in plaque size. Subtle analyses on the residue alterations uncovered the effects of five nucleotide mutations on the functions of the RNAP and capsid proteins, which account for the host-bursting efficiency. The deletion of two nucleotides in RNAP gene truncates the primary translation due to early stop codon, while a second translational peptide starting from GTG just at deletion point can remediate the polymerase activity. Out of three mutations in major capsid gene, H53N mutation weakens the subunit assembly between capsomeres for the phage head; E313K reduces the fold binding between $\beta$-sheet and Spine Helix inside the peptide. Genome sequencing has been done for phage therapy and probiotics to detect a tiny mutation but great effects 
which can provide early prediction of treatment efficacy or potential side effects.

\section{Methods}

\section{Bacterial strains and growth conditions}

Vibrio strains were bought from the Bioresource Collection and Research Center, Taiwan, including $V$. alginolyticus ATCC 17749, V. carchariae ATCC 35084, V. damsela ATCC 33536, $V$. harveyi ATCC 14126, $V$. parahaemolyticus ATCC 17802, V. pelagius ATCC 25916, and V. vulnificus BCRC15431. The Vibrio strains were maintained in Bacto Brain Heart Infusion medium (BHI; Becton-Dickinson Co, USA) supplemented with $3 \% \mathrm{NaCl}$ (Panreac Quimica, France). For long-term preservation, bacteria were frozen at $-80^{\circ} \mathrm{C}$ in $\mathrm{BHI}$ supplemented with $1 \% \mathrm{NaCl}$ and $25 \%$ glycerol (Nihon Shiyaku, Japan). The strains were streaked onto modified seawater yeast extract (rich MSWYE) agar plates consisting of $23.4 \mathrm{~g} \mathrm{NaCl}, 6.98 \mathrm{~g} \mathrm{MgSO}{ }_{4 \_} 7 \mathrm{H}_{2} \mathrm{O}$, and $0.75 \mathrm{~g} \mathrm{KCl}$ in $1000 \mathrm{ml}$ distilled water [18]. The $\mathrm{pH}$ was adjusted to 7.6 with $1 \mathrm{~N} \mathrm{NaOH}$, followed by the addition of $5.0 \mathrm{~g}$ of proteose peptone (HIMEDIA Lab, India), $3.0 \mathrm{~g}$ of yeast extract (HIMEDIA Lab, India), and $20.0 \mathrm{~g}$ of agar per liter.

\section{Isolation and titer of bacteriophages}

Water samples were collected from aquaculture waterways in southern Taiwan between 2008 and 2010. The water was centrifuged at $10,000 \times g$ for 30 minutes, and the supernatants were filtered through a $0.45 \mu \mathrm{m}$ microfilter. After centrifugation and microfiltration, $20 \%$ MSWYE medium $[7,8]$ and $1 \%$ overnight-grown Vibrio alginolyticus were added to the filtrate and incubated at $25^{\circ} \mathrm{C}$ for $4-24$ hours to enrich the phage growth. The bacterial debris was removed by two centrifugations at $10,000 \times g$ for 30 minutes. After enriching the phages in the field samples with the target bacterium Vibrio alginolyticus for 4-16 hours, phage-containing supernatants were incubated with the indicator strain for $5 \mathrm{mi}-$ nutes, suspended in low-percentage agar (top agar), and plated onto solid agar plates, so the target strain would form a bacterial lawn with the formation of plaques. The ten largest plaques from each plate were picked and reamplified three times in bacterium-containing broth using a $5 \times$ volume ratio. The plaques were picked into $200 \mu \mathrm{l}$ MSWYE broth for further titer counting or production amplification. To prepare bacterial cells for determination of phage concentrations, the host Vibrio alginolyticus was freshly inoculated as a $1 \%$ volume of seed from overnight culture into $10 \mathrm{ml}$ of rich MSWYE broth, and it grew to an $\mathrm{OD}_{600}$ of 0.3-0.4 in about 2 hours. After a series of dilutions, $10 \mu \mathrm{l}$ of diluted phage were added to $200 \mu \mathrm{l}$ of bacterial cells, incubated for 5 minutes, mixed with $3 \mathrm{ml}$ of top agar (rich MSWYE with 0.5\% agar), and then poured onto the solid surface of a $2 \%$ agar plate. The plaques were counted in 3-5 hours; the titer per ml was calculated as $100 \times$ (dilution factor) $\times$ (plaque count).

\section{Electron microscopy}

Preparation of phage particles for electron microscopy has been described elsewhere [19]. In brief, bacteriophage particles were applied to parafilm to produce a spherical drop. Carbon-coated nitrocellulose films were fabricated on copper grids, which were placed face down on the sample drop for $1 \mathrm{~min}$ to absorb the particles. After being briefly washed twice in $10 \mu \mathrm{l}$ of $10 \mathrm{mM}$ Tris buffer ( $\mathrm{pH}$ 8) (Amresco, USA), the samples were then rinsed twice with freshly prepared $2 \%$ uranyl acetate (UA; Sigma-Aldrich, USA) in Tris- $\mathrm{HCl}(\mathrm{pH} \mathrm{8.0)}$ and stained for 60 seconds. Following each step of absorption, washing, and UA staining, the grids were blotted with filter paper until almost dry. The finished grids were dried in vacuo overnight. Images of phage particles were taken at a magnification of 40,000x and a defocus of $3 \mu \mathrm{m}$, using a 200-kV electron microscope (JEOL JEM-2010, equipped with a Gatan-832 CCD camera).

\section{DNA Preparation for bacteriophage}

For propagation of phage, $10 \mathrm{ml}$ of phage stock was added to $100 \mathrm{ml}$ of $V$. alginolyticus $\left(3 \times 10^{8} \mathrm{CFU} \mathrm{ml}{ }^{-1}\right)$ cultured in MSWYE and incubated in a shaker at $25^{\circ} \mathrm{C}$ for $3-5$ hours until the lysate was clear. The remaining cells and debris were removed by two centrifugation cycles at 10,000 $\times g$ for 30 minutes. The supernatant, with a titer of $2 \times 10^{10} \mathrm{PFU} \mathrm{ml} l^{-1}$, was stored at $4^{\circ} \mathrm{C}$ as a phage stock. To concentrate phages using a standard PEG protocol $[7,20]$, solid $\mathrm{NaCl}$ and polyethylene glycol 8000 (Fluka, Germany) were added, and precipitation was performed overnight at $4^{\circ} \mathrm{C}$. After centrifugation, the phage particles were resuspended in $2 \mathrm{ml}$ of SM buffer and treated with DNase I and RNase A (Sigma, USA) to remove contaminating nucleic acids from the host. The polyethylene glycol was extracted by adding an equal volume of chloroform (TEDIA, USA) until the interface was clear. The aqueous phase containing the phage was treated with proteinase $\mathrm{K}$ (Invitrogen, USA) and sodium dodecyl sulfate (SDS; MD Bio, Inc., USA) at $56^{\circ} \mathrm{C}$ for $1 \mathrm{~h}$. Phenol extraction was carried out three times at room temperature, and the aqueous phase was further extracted with a 1:1 mixture of equilibrated phenol (Sigma, USA) and chloroform. DNA precipitated by a $2 \mathrm{x}$ volume of cold ethanol was redissolved in deionized water.

\section{Adsorption and phage burst size}

As described previously $[7,8]$ for the adsorption of phage on bacteria, $1 \mathrm{ml}$ of broth containing host cells and phages was taken at the 5th and 10th minutes and centrifuged to remove bacteria and bound phage, and free phage in the supernatants was then measured. Similarly, 
the burst size was measured as described previously [7]. In brief, $V$. alginolyticus cells were grown in $20 \mathrm{ml}$ of medium to mid-exponential phase $\left(\mathrm{OD}_{600}=0.3-0.5\right)$ and mixed with $0.1 \mathrm{ml}$ phage solution $(\mathrm{MOI}=1)$. Samples of $1 \mathrm{ml}$ of the mixture were taken at intervals and immediately subjected to centrifugation at $14,000 \times g$ for $3 \mathrm{mi}-$ nutes to remove bacteria. The phage titers in the solutions were determined by the agar overlay technique. Using the growth curve for $\mathrm{MOI}=1$ according to the one-step criteria, the burst size (Bs) of phage was calculated as $\mathrm{Bs}=\mathrm{Pt} / \mathrm{P} 0$, where $\mathrm{Pt}$ is the phage titer at that plateau phase and $\mathrm{PO}$ is the initial infective titer.

\section{Genome sequencing and annotation}

Similar to the shotgun sequencing described elsewhere, approximately $5 \mu \mathrm{g}$ of the bacteriophage genomic DNA was randomly sheared by nebulization, and DNA sequencing was performed at Mission Biotech according to the manufacturer's protocol for the Genome Sequencer GS Junior System (Roche Diagnostic). Low quality sequences of the reads generated by the GS Junior sequencer were trimmed off. De novo assembly of the shotgun reads was performed with the GS Assembler software. Sequence assembly and analyses were performed essentially as previously described. Protein-encoding genes (PEG) were predicted using The RAST Server (Rapid Annotations using Subsystems Technology; http://rast.nmpdr.org/) [21] and analyzed with the SEED-Viewer (http://www.theseed. org/wiki/Main_Page) [22]. Protein-coding genes were also checked using the $a b$ initio gene-finding program Glimmer v3.02 [23]. rRNA and tRNA genes of the draft assembly were identified using RNAmmer [24] and tRNAscan-SE [25]. Automatic functional annotation results obtained by the RAST were further compared with the proteins in the GenBank database using PSI-BLAST (www.ncbi.nlm.nih.gov/blast/Blast.cgi). The repeat units in the phage genomes were found by UGENE tool [26] and further aligned to acquire the consensus regions. The phage rho-independent terminators were predicted by ARNold with the criteria of both Erpin and RNAmotif selections [27]. The genomes of $\phi A 318$ and $\phi A s 51$ were submitted to GenBank with access no. KF322026 and KF800937, respectively [GenBank:KF322026; GenBank: KF800937].

\section{Multiple sequence alignment}

To determine the classification status of the newly isolated $\phi A 318$ and $\phi A s 51$ phages, sequence data for the genes encoding the DNA polymerase, DNA ligase, RNA polymerase, single-strand DNA binding protein, and capsid proteins of enterobacteria phages (T7, SP6, K1E, and K1F) and Vibrio cholerae phages (N4, VP4, and ICP3) were employed to find highly homologous regions. Complete genome sequences of four enterobacteria phages and three Vibrio Podoviridae phages were acquired from National Center for Biotechnology Information, NIH, USA: T7 (39,937 bp) [GenBank:NC_001604], SP6 (43,769 bp) [GenBank:NC_004831], K1E (45,251 bp) [GenBank:NC_007637], K1F (39,704 bp) [GenBank: NC_007456], ICP3 (39,162 bp) [GenBank:NC_015159], N4 (38,497 bp) [GenBank:NC_013651], and VP4 (39,503 bp) [GenBank:NC_007149]. The T7 RNA polymerase sequence is also the same as PDB:1QLN (RCSB-PDB ID), and SP6 RNA polymerase is from NC_004831 [GenBank: NC_004831]. The threading predictions by PHYRE ver2 [15] were iterated to predict the tertiary structures of $\phi A 318$ and $\phi A s 51$ RNA polymerase.

Sequences of individual genes which were retrieved from the genome sets were then aligned using ClustalW with default options [28]. The complete RNA polymerase sequences were analyzed by the neighbor-joining method using the NEIGHBOR program in Phylogeny Inference Package (PHYLIP) [29]. Distances were calculated using the DNADIST program of PHYLIP and displayed in TreeView. ClustalW, PHYLIP, and TreeView were bundled in the BioEdit program version 7.0.5 [30]. The multiple sequence alignment for the phage genomes was constructed in the Mauve using MUSCLE3.6 algorithm [31].

\section{Additional files}

Additional file 1: phiA318.gbk. It is in GenBank format. Annotation for фA318 genome.

Additional file 2: phiAs51.gbk. It is in GenBank format. Annotation for фAs51 genome.

\section{Competing interests}

The authors declare that they have no competing interests.

\section{Authors' contributions}

CSL conducted the study and wrote the manuscript. CSL and YRL did the experiments. CSL, WL, MWL, PJS and WHW analyzed the sequences and functions. All authors read and approved the final manuscript.

\section{Acknowledgements}

This research fund is partially supported by grants from the National Science Council, Taiwan (NSC99-2313-B-110-002-MY3 and NSC102-2313-B110-002-MY3), and the Ministry of Education, Taiwan (NSYSU95-99C031701; the second term of Top University Program: NSYSU00-02C030205 and NCHU 100-S05-09) under the ATU plan. We thank Professors Hsueh-Wen Chang, $\mathrm{MH}$ Tai, Chih-Chuang Liaw, Chen-Tung Arthur Chen and Houng-Yung Chen, as the grant organizers of the ATU plan. Also we appreciate Kenneth B. Lin and Dr. Simon White for comments and editing.

\section{Author details}

'Department of Marine Biotechnology and Resources, Asia-Pacific Ocean Research Center, National Sun Yat-sen University, Kaohsiung 80424, Taiwan. 2Department of Biotechnology, Kaohsiung Medical University, Kaohsiung, Taiwan. ${ }^{3}$ Department of Aquaculture, National Taiwan Ocean University, Keelung, Taiwan. ${ }^{4}$ National Museum of Marine Biology and Aquarium, Pingtung 944, Taiwan.

Received: 18 November 2013 Accepted: 30 May 2014

Published: 21 June 2014 


\section{References}

1. Baffone W, Citterio B, Vittoria E, Casaroli A, Pianetti A, Campana A, Bruscolini F: Determination of several potential virulence factors in Vibrio spp. isolated from seawater. Food Microbiol 2001, 18:479-488.

2. Balebona MC, Andreu MJ, Bordas MA, Zorrilla I, Morinigo MA, Borrego JJ: Pathogenicity of Vibrio alginolyticus for cultured gilt-head sea bream (Sparus aurata L.). Appl Environ Microbiol 1998, 64(11):4269-427528.

3. Kahla-Nakbi AB, Chaieb K, Besbes A, Zmantar T, Bakhrouf A: Virulence and enterobacterial repetitive intergenic consensus PCR of Vibrio alginolyticus strains isolated from Tunisian cultured gilthead sea bream and sea bass outbreaks. Vet Microbiol 2006, 117(2-4):321-327.

4. Simidu U, Noguchi T, Hwang DF, Shida Y, Hashimoto K: Marine bacteria which produce tetrodotoxin. Appl Environ Microbol 1987, 53(7):1714-1715.

5. Efrony R, Atad I, Rosenberg E: Phage therapy of coral white plague disease: properties of phage BA3. Curr Microbiol 2009, 58(2):139-145.

6. Seed KD, Bodi KL, Kropinski AM, Ackermann HW, Calderwood SB, Qadri F, Camilli A: Evidence of a dominant lineage of Vibrio cholerae-specific lytic bacteriophages shed by cholera patients over a 10-year period in Dhaka, Bangladesh. MBio 2011, 2(1):e00334-10.

7. Lin Y-R, Chiu C-W, Chang F-Y, Lin C-S: Characterization of a new phage, termed $\phi A 318$, which is specific for Vibrio alginolyticus. Arch Virol 2012, 157:917-926.

8. Lin Y-R, Lin C-S: Genome-wide characterization of Vibrio phage $\phi p p 2$ with unique arrangements of the mob-like genes. BMC Genomics 2012 13:224-237.

9. Altschul SF, Gish W, Miller W, Myers EW, Lipman DJ: Basic local alignment search tool. J Mol Biol 1990, 215:403-410.

10. Stummeyer K, Schwarzer D, Claus H, Vogel U, Gerardy-Schahn R, Mühlenhoff M: Evolution of bacteriophages infecting encapsulated bacteria: lessons from Escherichia coli K1-specific Phages. Mol Microbiol 2006, 60(5):1123-1135.

11. Lind $\mathrm{PA}$, Anderson DI: Whole-genome mutational biases in bacteria. Proc Natl Acad Sci U S A 2008, 105(46):7878-17883.

12. Cheetham GM, Steitz TA: Structure of a transcribing T7 RNA polymerase initiation complex. Science 1999, 286(5448):2305-2309.

13. Bradley DE: Ultrastructure of bacteriophages and bacteriocins. Bacteriol Rev 1967, 31(4):230-314.

14. Mitra S, Basu S: Some biophysical properties of a vibriophage and its DNA. Biochim Biophys Acta 1968, 155(1):143-149.

15. Kelley LA, Sternberg MJE: Protein structure prediction on the web: a case study using the Phyre server. Nat Protoc 2009, 4:363-371.

16. Ionel A, Velázquez-Muriel JA, Luque D, Cuervo A, Castón JR, Valpuesta JM, Martín-Benito J, Carrascosa JL: Molecular rearrangements involved in the capsid shell maturation of bacteriophage T7. J Biol Chem 2011, 286:234-242.

17. Veesler D, Quispe J, Grigorieff N, Potter CS, Carragher B, Johnson JE: Maturation in action: cryoEM study of a viral capsid caught during expansion. Structure 2012, 20(8):1384-1390.

18. Schwarz JR, Colwell RR: Effect of hydrostatic pressure on growth and viability of Vibrio parahaemolyticus. Appl Microbiol 1974, 28:977-981.

19. Lu M-W, Liu W, Lin C-S: Infection competition against grouper nervous necrosis virus by virus-like particles produced in Escherichia coli. J Gen Virol 2003, 84:1577-1582

20. Sambrook J. Russell DW: Molecular cloning: a laboratory manual. 3rd edition. Cold Spring Harbor: Cold Spring Harbor Laboratory Press; 2001.

21. Aziz RK, Bartels D, Best AA, Dejongh M, Disz T, Edwards RA, Formsma K, Gerdes S, Glass EM, Kubal M, Meyer F, Olsen GJ, Olson R, Osterman AL, Overbeek RA, McNeil LK, Paarmann D, Paczian T, Parrello B, Pusch GD, Reich C, Stevens R, Vassieva O, Vonstein V, Wilke A, Zagnitko O: The RAST server: rapid annotations using subsystems technology. BMC Genomics 2008, 9:75-89.

22. Overbeek R, Begley T, Butler RM, Choudhuri JV, Chuang HY, Cohoon M, de Crécy-Lagard V, Diaz N, Disz T, Edwards R, Fonstein M, Frank ED, Gerdes S, Glass EM, Goesmann A, Hanson A, Iwata-Reuyl D, Jensen R, Jamshidi N, Krause L, Kubal M, Larsen N, Linke B, McHardy AC, Meyer F, Neuweger H, Olsen G, Olson R, Osterman A, Portnoy V, et al: The subsystems approach to genome annotation and its use in the project to annotate 1000 genomes. Nucleic Acids Res 2005, 33(17):5691-5702.
23. Delcher AL, Bratke KA, Powers EC, Salzberg SL: Identifying bacterial genes and endosymbiont DNA with glimmer. Bioinformatics 2007, 23(6):673-679.

24. Lagesen K, Hallin PF, Roland EA, Stafeldt HH, Rognes T, Ussery DW: RNammer: consistent annotation of rRNA genes in genomic sequences. Nucleic Acids Res 2007, 35(9):3100-3108.

25. Lowe TM, Eddy SR: tRNAscan-SE: a program for improved detection of transfer RNA genes in genomic sequence. Nucleic Acids Res 1997, 25:955-964

26. Okonechnikov K, Golosova O, Fursov M: Unipro UGENE: a unified bioinformatics toolkit. Bioinformatics 2012, 28:1166-1167.

27. Macke T, Ecker D, Gutell R, Gautheret D, Case DA, Sampath R: RNAMotif - A new RNA secondary structure definition and discovery algorithm. Nucleic Acids Res 2001, 29:4724-4735.

28. Thompson JD, Higgins DG, Gibson TJ: CLUSTAL W: improving the sensitivity of progressive multiple sequence alignment through sequence weighting, position-specific gap penalties and weight matrix choice. Nucleic Acids Res 1994, 22:4673-4680.

29. Felsenstein J: PHYLIP—Phylogeny Inference Package (Version 3.2). Cladistics 1989, 5:164-166.

30. Hall TA: BioEdit: a user-friendly biological sequence alignment editor and analysis program for Windows 95/98/NT. Nucleic Acids Symp Ser 1999, 41:95-98.

31. Darling AE, Mau B, Perna NT: progressiveMauve: Multiple Genome Alignment with Gene Gain, Loss, and Rearrangement. PLOS One 2010, 5(6):e11147.

32. Alikhan NF, Petty NK, Ben Zakour NL, Beatson SA: BLAST Ring Image Generator (BRIG): simple prokaryote genome comparisons. BMC Genomics 2011, 12:402.

doi:10.1186/1471-2164-15-505

Cite this article as: Liu et al.: Genome sequences characterizing five mutations in RNA polymerase and major capsid of phages $\phi A 318$ and $\phi$ As51 of Vibrio alginolyticus with different burst efficiencies. BMC Genomics 2014 15:505.

\section{Submit your next manuscript to BioMed Central and take full advantage of:}

- Convenient online submission

- Thorough peer review

- No space constraints or color figure charges

- Immediate publication on acceptance

- Inclusion in PubMed, CAS, Scopus and Google Scholar

- Research which is freely available for redistribution 